\title{
So-called neuronal ceroid lipofuscinosis
}

\author{
Neurophysiological studies in 60 children
}

\author{
G. PAMPIGLIONE AND A. HARDEN
}

From the Department of Neurophysiology, The Hospital for Sick Children, Great Ormond Street, London

S UMM ARY Combined EEG, ERG, and VEP studies were carried out in 60 children with verified neuronal storage of ceroid/lipofuscin-like material. Comparing and contrasting the EEG/ERG/VER features of each child during the symptomatic phase of the disease, three distinct main groups could be recognised: (1) Progressive diminution in amplitude of the EEG and VEP beginning about the age of 2 years was seen in seven children, and all phasic cerebral activity was unrecordable at 3-4 years of age; the clinical onset with regression in skills began at 1-2 years of age ; (2) Large amplitude irregular slow activity and polyphasic spikes appeared in 27 children in whom characteristic discharges were elicited at low rates of photic stimulation (grossly enlarged VEP); the clinical onset was around 3 years of age with an occasional seizure and some clumsiness; (3) Runs of slow wave and spike complexes were seen in the EEG of 10 children with a small or absent VEP; the clinical onset with visual failure began around 5-7 years of age. In the remaining 16 children, the EEG and the clinical features fell into much smaller groups, possibly of rarer type. The ERG became unrecordable at an early symptomatic phase in all 60 children. The present findings suggest that such umbrella terms as neuronal ceroid lipofuscinosis or Batten's disease, which imply a single disease entity, are misleading. Neurophysiological investigations can help in an early identification of these separate conditions. When the biochemical basis of these disorders becomes fully understood a more rational nomenclature will be possible.

At the turn of the century, the syndrome of amaurotic family idiocy included inherited, progressive, neurological disorders with some clinical features in common (intellectual deterioration, seizures, visual failure, and fatal outcome). Histological studies showed extensive cellular lesions in the central nervous system with intracellular accumulation of material recognisable by appropriate staining techniques. The term cerebral or neuronal lipidosis was loosely applied by pathologists to include the groups of disorders that were known to clinicians as amaurotic family idiocy. These were classified according to age of onset and given a variety of eponymous labels as shown in the Table.

Since the chemical nature of the stored material in Tay-Sachs disease was identified as ganglioside (Klenk, 1942), this infantile form became recognised as a separate entity, different from the other groups of amaurotic family idiocy in which the biochemistry of the underlying defect has not yet been elucidated. However, the intracellular stored material in all the
Table Old classification of amaurotic family idiocy in childhood

\begin{tabular}{ll}
\hline Infantile form & Tay (1881) \\
& Sachs (1887) \\
Late infantile form & Jansky (1908) \\
& Bielschowsky (1913) \\
& F. E. Batten (1914) \\
Juvenile form & R. D. Batten (1897) \\
& F. E. Batten (1903) \\
Mayou (1904) & Vogt (1905) \\
& Spielmeyer (1905) \\
& Sjögren (1931) \\
\hline
\end{tabular}

other groups has fairly uniform staining reactions similar to ceroid and/or lipofuscin, a 'wear and tear' pigment that is a normal accompaniment of aging. For this reason, the term neuronal ceroid lipofuscinosis was introduced by Zeman and Dyken in 1969 to include all forms of amaurotic family idiocy except Tay-Sachs disease. The term neuronal ceroid lipofuscinosis has also been used for a new infantile form of storage disease with similar histochemical features first described in Finland by Haltia et al. 
(1973) and Santavuori et al. (1973). In England the term Batten's disease and neuronal ceroid lipofuscinosis are both often used to include all these various forms of storage disease with intracellular accumulation of ceroid/lipofuscin-like material.

As the electrical activity of the brain recorded in the electroencephalogram (EEG) is a sensitive indicator of cerebral metabolism, it is not surprising that EEG abnormalities accompany the accumulation of neuronal metabolites. In addition, as the visual system is commonly involved in these conditions, it might be expected that the electroretinogram (ERG), and the cortical visual evoked potentials (VEP), would also be altered.

At this hospital since 1968 some 3000 children with a variety of suspected cerebral and/or visual disorders have been studied, using a combined EEG, ERG, and VEP procedure. In some groups of patients with histologically proven neuronal ceroid lipofuscinosis, characteristic combinations of EEG/ERG/VEP features have been considered to be of diagnostic importance (Harden et al., 1973; Pampiglione and Harden, 1973, 1974). In the present paper the EEG, ERG, and VEP findings in all cases of histochemically proven neuronal ceroid lipofuscinosis seen over the last eight years are compared and contrasted in order to establish some differential neurophysiological criteria.

\section{Patients and methods}

Out of a large number of children examined, there were 60 patients in whom the presence of neuronal storage of ceroid/lipofuscin-like material had been verified from biopsy material taken from the rectum (Brett and Lake, 1975). In most of these children neurophysiological investigations had been carried out before the diagnosis was verified histochemically. Most of them had been referred to our Department because of somewhat unspecific symptoms, such as developmental delay, clumsiness, occasional seizures, or visual difficulties. All the patients had been admitted to the Hospital for Sick Children. The EEGs were carried out with a uniform technique, and the silver-silver chloride electrodes were attached to the scalp with collodion according to measurements from bony landmarks (Pampiglione, 1956). The combined techniques of EEG, ERG, and VEP were carried out according to methods previously described (Harden and Pampiglione, 1970).

The age of onset of the main clinical symptoms and the course of the disease were noted in all the patients, most of whom had repeated neurophysiological investigations at intervals ranging from a few months to several years. A total of 165 EEGs were taken on these patients, and 125 combined ERG/VEP studies were also made. The occurrence of seizures or behavioural changes of other kinds during these tests was also noted, as well as the clinical condition of the child at the time of each test. Particular attention was devoted to the evolution of the neurophysiological features during the follow-up period in the various age groups.

\section{Results}

The onset of insidious symptoms such as 'failure to thrive', 'behaviour problem', or 'delayed milestones' was difficult to establish despite their probable importance in the early stages of any illness. For this reason the more definite loss of skills, the first seizure, or obvious visual difficulties were considered in reckoning the age of onset of the clinical illness in our 60 patients (Fig. 1).

When the EEGs taken during the symptomatic phase were studied, the patients could be divided into distinct groups showing the following features:

\section{DECREASE IN AMPLITUDE OF EEG ACTIVITY}

There were seven children in whom the phasic EEG activity gradually diminished in amplitude to the extent of electrocerebral silence in those tested over the age of 4 years. The ERG and VEP also gradually disappeared over the same time. The age of onset of the illness was between 1 and 2 years, the presenting features being in all cases a loss of skills. The clinical symptoms progressed rapidly over a period of two to three years so that the patients were reduced to a vegetative state, although survival could be prolonged for several years up to the age of 8-10 years. These features are similar to those described in Finland by Santavuori et al. (1974).

2. LARGE AMPLITUDE EEG ACTIVITY WITH DISCHARGES ELICITED BY LOW RATES OF PHOTIC STIMULATION

In 27 children showing these EEG features there were also irregular slow waves and polyphasic spikes in the resting record, and the first seizure (taken as the onset of illness) was at around 3 years of age. The ERG rapidly disappeared although it was still present in some cases for a short time at the onset of clinical symptoms. The large spikes seen in the EEG during photic stimulation were in fact the grossly enlarged early components of the VEP. The EEG features including the large abnormal discharges in response to low rates of photic stimulation persisted throughout the course of the illness. Seizures became increasingly frequent and myoclonic jerks, clumsiness, mental and motor retardation became more obvious (as clinically described in one case by Jansky (1908) and in a family by Bielschowsky in 1913). Death usually occurred at the age of 6-7 years. 


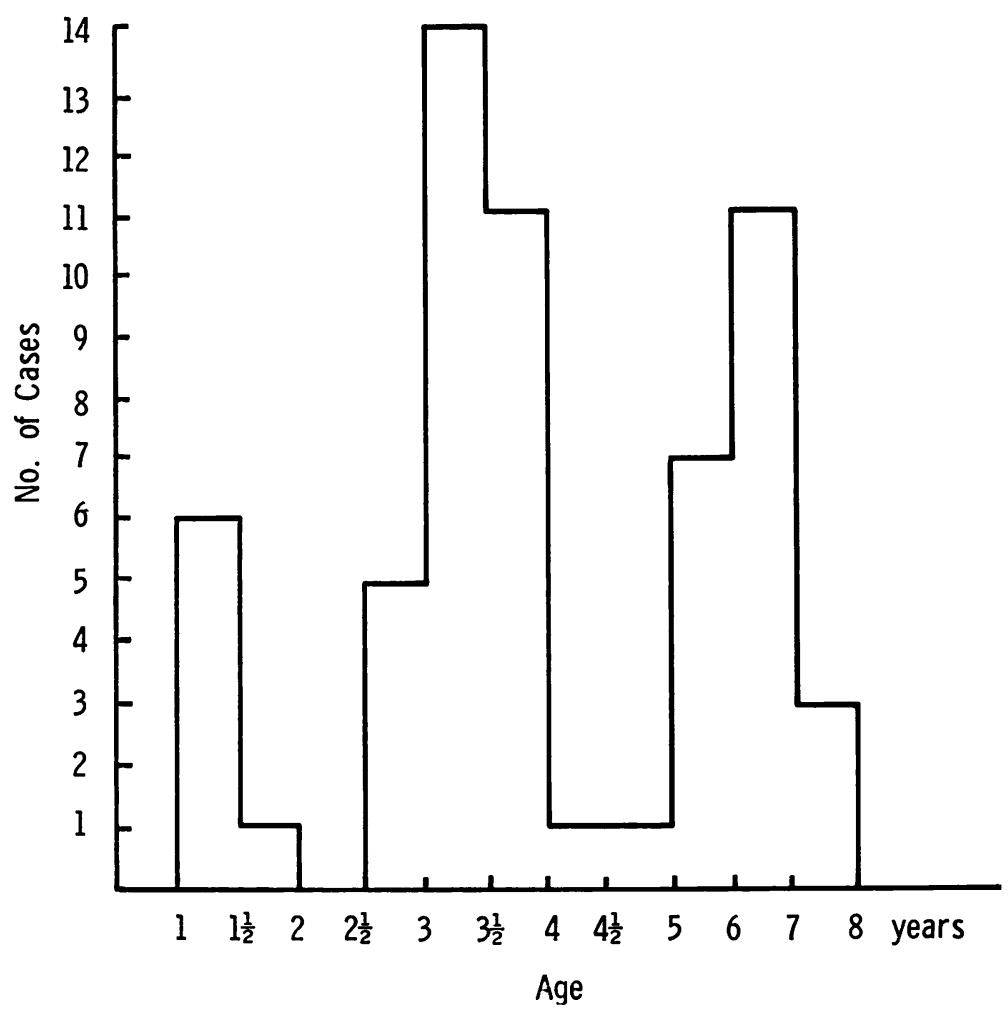

Fig. 1 Age of onset of definite clinical symptoms in 60 children (1968-1975)

3. RUNS OF LARGE AMPLITUDE SLOW WAVE AND SPIKE COMPLEXES IN THE EEG

There were 10 children who showed these EEG features. The main symptom of deterioration of vision had been noticed around $4 \frac{1}{2}-7$ years of age in all of them. The ERG was not recordable from an early stage while the VEP gradually became of low amplitude, particularly in its early components, and in some cases was unrecordable. Clinically these children became blind with slow but progressive mental deterioration and infrequent seizures, although not all these 10 children had yet had seizures. Death did not occur for a number of years, the patient usually surviving into the third decade. The clinical course of these patients was similar to that described by Spielmeyer (1905) and Vogt (1905).

4. OTHER TYPES OF EEG FEATURES WITH SYMPTOMS OF THE SPIELMEYER TYPE

In seven children with age of onset and symptomatology similar to the Spielmeyer cases of group 3 as above, the EEG did not show the distinctive runs of slow wave and spike complexes even after a long-term follow-up. Seizures had also occurred in some of these patients, and the EEGs all showed definite abnormalities but with somewhat variable morphological

features. The ERG and VEP findings were similar to the other Spielmeyer type patients.

5. A MISCELLANY OF EEG/ERG/VEP COMBINATIONS AND CLINICAL SYMPTOMS

There were eight children in whom the age of onset and clinical course were variable. In all these patients, however, there were EEG and VEPabnormalities, and the ERG was unrecognisable from an early phase of the symptomatic illness. There was also another child, seen only once at the time of her first seizure (age $2 \frac{1}{2}$ years), and probably too early in the course of the disease to have developed the discharges at low rates of photic stimulation which were clearly seen in the EEG of her older sibling with the Bielschowsky form of the disease. The ERG was still present in this one young sibling who has not had follow-up studies.

In Fig. 2 the distinctive EEG features of 1, 2, and 3 above are compared at a fairly advanced stage of the clinical illness. The EEG findings did not depend on the age at which the EEG was taken during the course of each illness. Figure 3 shows three other children with the distinctive EEG features of each group 1, 2, and 3 above, but all taken at the same age ( 7 years) though at different phases of clinical evolution. Again 
SANTAUUORI ACE 4

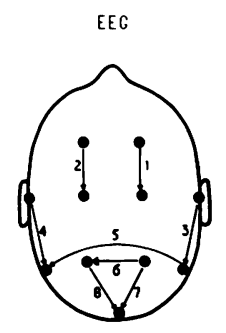

ERG

UER

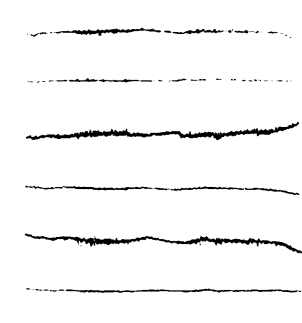

100

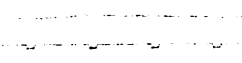

ABSENT
BIELSCHOWSKY ACE 5

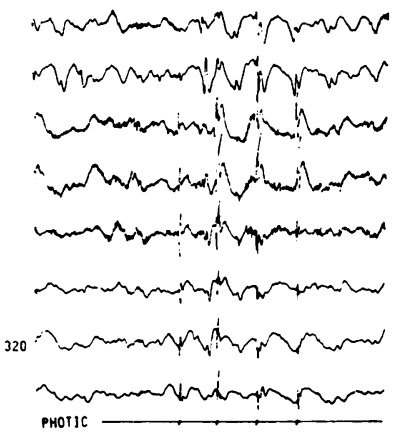

ABSENT
SPIELMEYER ACE 12

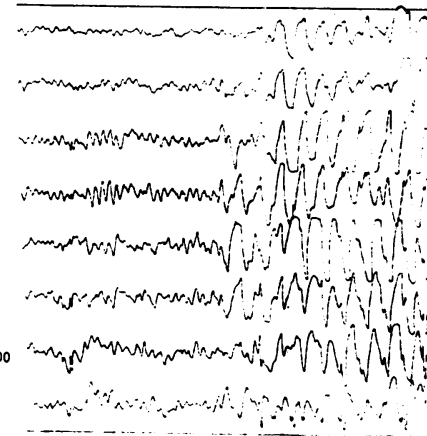

ABSENI

Fig. $2 E E G, E R G$, and VEP features during advanced symptomatology of three main types of so-called neuronal ceroid lipofuscinosis (see 1,2, and 3 in results section). In EEG of middle tracing note different gain used and marker for each flash of photic stimulation on bottom line. Time scale in seconds is indicated underneath EEG of left hand tracing, and is the same for all three samples

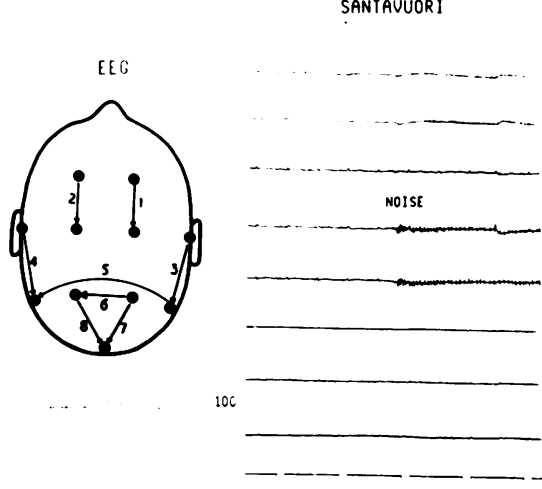

ERG

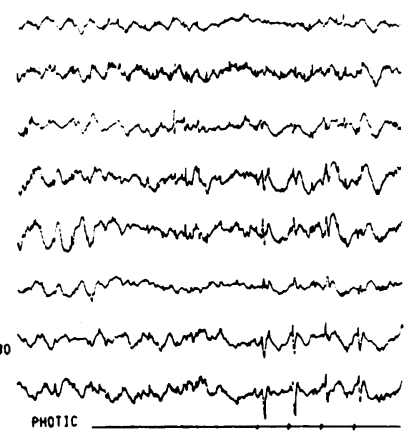

ABSENT
SPIELMEYER

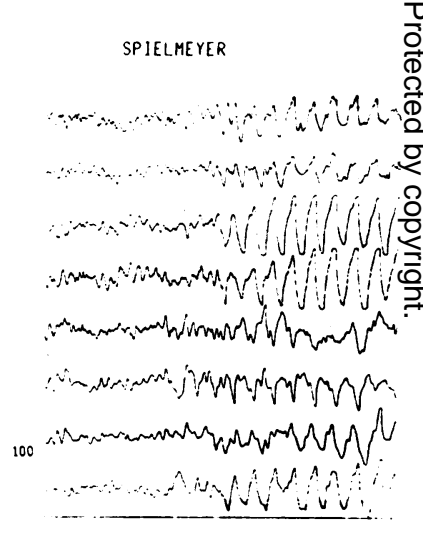

ABSENI

UER

ABSENT

GROSSLY EMLARCEO EARLY COMPONENTS

REDUCED EARLY COMPONENTS

Fig. $3 E E G, E R G$, and VEP features in three main types of so-called neuronal ceroid lipofuscinosis in three patients all aged 7 years.

the EEG features remained typical of each type, and never evolved from one to another in any patient followed over several years. The EEG and VEP findings are indicated in Figs. 2 and 3, while in Fig. 4 they are contrasted with those of a normal child. The EEG/ERG/VEP findings and the clinical course were always identical in affected siblings.

Figure 5 summarises the main groups of clinical conditions in relation to the age of clinical onset and the main EEG features, after exclusion of the eight cases not easily classifiable and the younger sibling seen only once at the onset of symptoms.

\section{Discussion}

Many children are referred for neurophysiological studies with a history of fits and retardation, a suggestion of some regression in skills, or a possible $\underset{\omega}{N}$ visual loss, but only very few of these have a degenera- $\bar{\sigma}$ 


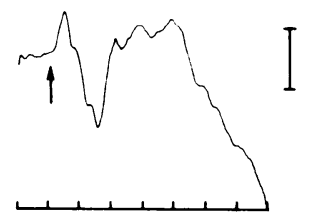

NORMAL CONTROL

ACE 1

SANTAUUORI

AGE 4

BIELSCHOWSKY

AGE 4

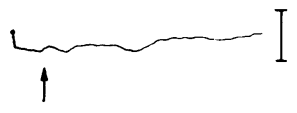

SPIELMEYER AGE 11

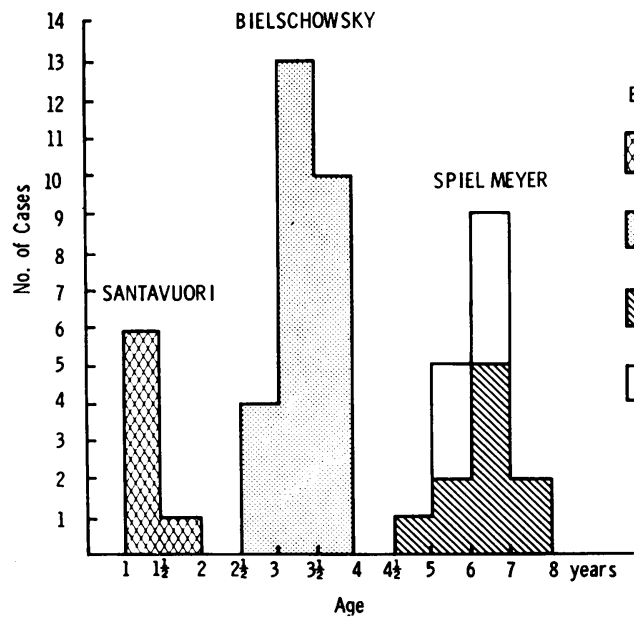

EEG features
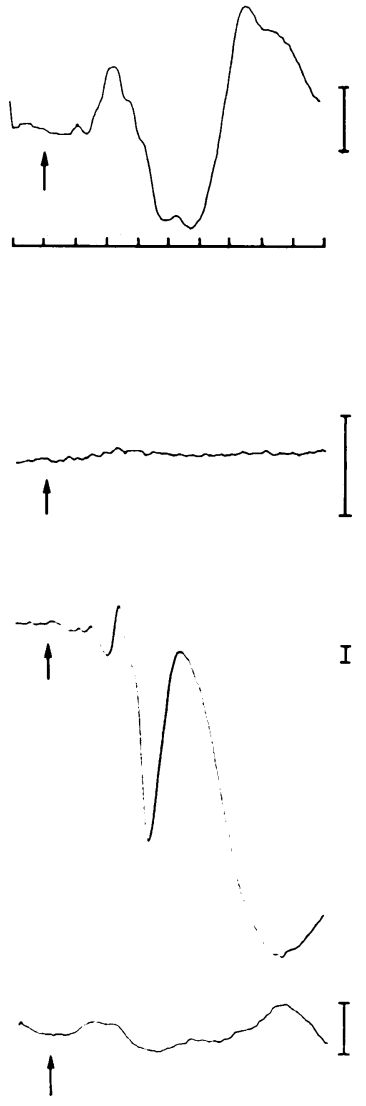

Low amplitude EEG

Spikes at low rate of photic stimulation

Runs of slow complexes

Fig. 5 Main EEG features in relation to three types of clinical evolution and to age of onset

Fig. 4 ERG and VEP findings in a normal child (top tracings) for comparison with findings in three main types of so-called neuronal ceroid lipofuscinosis (see 1, 2 and 3 in results section). Both eyes are stimulated simultaneously while open; the ERG is recorded from a non-corneal electrode placed on the bridge of the nose and the VEP from a mid-occipital electrode on the scalp. Negativity is recorded as an upward deflection. Analysis time for ERG is $200 \mathrm{~ms}$ and VEP is 250 ms. (25 ms interval time scale shown under tracings of normal control.) Flash stimulus occurs 25 ms after onset of analysis and is indicated by arrow. Calibration signal $10 \mu \mathrm{V}$; note different sizes of calibration signals (especially the attenuation for the VEP of the Bielschowsky type patient). The deflections seen around $50 \mathrm{~ms}$ in the ERG of the Bielschowsky type patient are of cerebral rather than retinal origin.

Other types of abnormalities 
tive disorder. The diagnosis of neuronal ceroid lipofuscinosis can only be made from histochemical studies on biopsy material, and this procedure can be properly carried out in only a few centres. On clinical grounds alone, a decision for biopsy may not be reached for a long time after the onset of symptoms. The EEG, supplemented by ERG/VEP studies, can play a very important role in suggesting such disease processes at a relatively early symptomatic phase. Although there is no known cure for these autosomal, recessive, genetically determined, neurometabolic disorders, an early diagnosis is of the utmost importance in relation to genetic counselling and the prevention of further family tragedies. In our series there were nine families with more than one affected child. It is likely that histochemical changes precede any of the characteristic clinical and neurophysiological features but our experience is not yet large enough to assess the predictive value of the EEG findings in the presymptomatic phases.

Green (1971) reported the neurophysiological findings in 20 patients aged 2-23 years of age with socalled Batten's disease, and considered the differing EEG and clinical patterns as part of a continuum in the progression of the same process. In contrast, we have found that the combinations of EEG/ERG/VEP findings are of diagnostic importance in distinguishing at least three different conditions with apparently similar storage of neuronal ceroid material. In the early stages of the illness, regular follow-up is very important, especially in the Santavuori type when the progressively decreasing amplitude of the EEG becomes apparent (Santavuori, 1973; Pampiglione and Harden, 1974). All the 60 children examined in our series showed EEG patterns quite different from those seen in other neurometabolic storage disorders such as Tay-Sachs disease (Pampiglione et al., 1974), Krabbe's leucodystrophy (Kliemann et al., 1969), or metachromatic leucodystrophy (Mastropaolo et al., 1971).

Focal spikes and multifocal discharges in the EEG are commonly seen in a wide variety of patients with seizures. Abnormal discharges in response to photic stimulation are not uncommon (Jeavons and Harding, 1975), but these are usually elicited at flash rate frequencies around 12-24 per sec, and not as a response to a single flash as seen in the Bielschowsky type of patient. None of the 60 children of our present series had EEGs that could be confused with the EEG features of hypsarrhythmia. In other children with seizures, spike and wave phenomena in various forms may be seen but these discharges are of somewhat different configuration from those of the Spielmeyer group even in the so-called Lennox syndrome. Runs of slow wave and spike have been described previously in other patients belonging to the Spielmeyer group (Pampiglione and Lehovský, 1968; Ellingson and Schain, 1969). It is also interesting to note that the children with runs of slow wave and spike complexes with neuronal ceroid lipofuscinosis were referred because of failing vision; some had not yet developed seizures, and certainly none had ever had clinical petit mal epilepsy. This emphasises the importance of combined EEG/ERG/VEP studies on young patinets even if only a primary visual problem is suspected.

The conditions we have described are rare, the Bielschowsky type being the most common in our series, and probably also the easiest to recognise on the basis of the primary EEG traces. The very characteristic response to low rates of photic stimulation in these patients can only be elicited if appropriate techniques are employed taking care that the patient actually looks at each flash of the lamp. Since the diagnostic importance of the unusual response to photic stimulation in the Bielschowsky type patients was originally suggested (Pampiglione, 1961; Pampiglione and Lehovský, 1968), there have been a few reports from other centres confirming the diagnostic value of these EEG features (Lehovský, 1971 ; Gordon et al., 1972; López Martín et al., 1974). It seems likel that more patients with the Bielschowsky type of dis order will be identified on EEG findings when greater awareness of the problem develops, as oce curred after the description of specific EEG feature in subacute sclerosing panencephalitis. It may be interesting to note that in this hospital over the perios of the present study (1968-1975), there has been higher incidence of Bielschowsky type patients than patients with SSPE.

The only neurophysiological finding common to all the 60 patients of the present study was the early loss of the ERG. It is believed that the outer receptor layers of the retina (rods and cones) contain storage material in all cases of so-called neuronal ceroid lipofuscinosis. This is in marked contrast to patients with Tay-Sachs disease where only the ganglion cell layer of the retina is affected, and the ERG is preserved throughout the whole of the illness (Copenhaver and Goodman, 1960; Pampiglione et al., 1974). Pigmentary changes in the retina and optic atrophy were reported at some stage in many of our 60 patients, but no systematic ophthalmological study has been carried out, and there have been very few reports on the eye histopathology of these patients. An absent ERG does not necessarily imply total loss of retinal function, and may be found with preservation of some cortical VEP in a variety of conditions. However a grossly enlarged VEP, as seen in the Bielschowsky type, together with the early loss of ERG, is not seen in other conditions, and appears to be of considerable theoretical importance although the underlying mechanism is not yet understood. It is 
perhaps interesting in this context that visual loss was not clinically obvious in these children until they were grossly demented at an advanced stage of the disease.

There has been much confusion in the nomenclature and classification of disorders with storage of ceroid/lipofuscin-like material, and a mixture of eponymous and neuropathological labels has been used. It is obvious that the term amaurotic family idiocy is now outdated (Lancet, 1973), and that these disorders may not be labelled confidently as lipidoses as the biochemical nature of the stored material is still unknown. The use of umbrella terms such as neuronal ceroid lipofuscinosis and Batten's disease gives the impression of a single nosological entity. However, from our studies it seems apparent that there are at least three distinct types, each with its own characteristic clinical course and neurophysiological findings, and each presumably has different enzyme defects. The fact that some children with apparently typical clinical course of Spielmeyer type showed different EEG patterns from those of the main larger group, would lead us to suspect that there may be more than one variety of Spielmeyer type patients with somewhat differing biochemical dysfunctions. The eight cases with very mixed clinical courses and neurophysiological findings also seem likely to be made up of rarer groups. Only when the biochemical basis of these disorders is fully understood can a rational nomenclature be properly introduced. In the meantime, the separation of different types on neurophysiological grounds should help not only in the identification of these disorders but also in classifying them into a number of separate disease entities.

It is a pleasure to thank our colleagues who referred the patients for neurophysiological investigations, in particular Dr E. M. Brett, Dr Rosemary Stephens, and Dr John Wilson, as well as Dr Brian Lake, who carried out the histochemical studies, and the Department of Medical Illustration. We are grateful to Dr Etta Friedman and Sir Charles Symonds for their comments.

\section{References}

Annotation (1973). Amaurotic family idiocy. Lancet, 1, 469-471.

Batten, F. E. (1903). Cerebral degeneration with symmetrical changes in the maculae in two members of a family. Transactions of the Ophthalmological Society of the United Kingdom, 23, 386-390.

Batten, F. E. (1914). Family cerebral degeneration with macular change (so-called juvenile form of family amaurotic idiocy). Quarterly Journal of Medicine, 7, 444-454.

Batten, R. D. (1897). Two brothers with symmetrical disease of the macula, commencing at the age $o^{f}$ fourteen. Transactions of the Opthalmological Society of the United Kingdom, 17, 48-49.

Bielschowsky, M. (1913). UUber Spatinfantile familiäre amaurotische Idiotie mit Kleinhirn Symptomen. Deutsche Zeitschrift für Nervenheilkwide, 50, 7-29.

Brett, E. M. and Lake, B. D. (1975). Reassessment of rectal approach to neuropathology in childhood. Archives of Disease in Childhood, 50, 753-762.

Copenhaver, R. M. and Goodman, G. (1960). The electroretinogram in infantile, late infantile and juvenile amaurotic family idiocy. Archives of Ophthalmology, 63, 559-566.

Ellingson, R. J. and Schain, R. J. (1969). EEG patterns in juvenile cerebral lipidosis. Electroencephalography and Clinical Neurophysiology, 27, 191-194.

Gordon, N. S., Marsden, H. B., and Noronha, M. J. (1972). Neuronal ceroid lipofuscinosis (Batten's disease). Archives of Disease in Childhood, 47, 285-291.

Green, B. (1971). Neurophysiological studies in Batten's disease. Developmental Medicine and Child Neurology, 13, 477-489.

Haltia, M., Rapola, J., Santavuori, P., and Keränen, A. (1973). Infantile type of so-called neuronal ceroidlipofuscinosis. Part 2. Morphological and biochemical studies. Journal of the Neurological Sciences, 18, 269-285.

Harden, A. and Pampiglione, G. (1970). Neurophysiological approach to disorders of vision. Lancet 1 , 805-809.

Harden, A., Pampiglione, G., and Picton-Robinson, N. (1973). Electroretinogram and visual evoked response in a form of 'neuronal lipidosis' with diagnostic EEG features. Journal of Neurology, Neurosurgery, and Psychiatry, 36, 61-67.

Jansky, J. (1908). Sur un cas jusqu'à présent non décrit d'idiotie amaurotique familiale compliqué par une hypoplasie du cervelet. Sbornik Vedeckých Prací Lékařské Fakulty Karlovy University v Hradci Králové, 9, 165-196.

Jeavons, P. M. and Harding, G. F. A. (1975). Photosensitive Epilepsy. Clinics in Developmental Medicine No. 56. Spastics International Medical Publications. William Heinemann Medical Books: London.

Klenk, E. (1942). Über die Ganglioside des Gehirns bei der infantilen amaurotischen Idiotie vom Typ TaySachs. Berichte der Deutschen Chemischen Gesellschaft (Berlin), 75B, 1632-1636.

Kliemann, F. A. D., Harden, A., and Pampiglione, G. (1969). Some EEG observations in patients with Krabbe's disease. Developmental Medicine and Child Neurology, 11, 475-484.

Lehovský, M. (1971). Pomoc elektroencefalografie v diagnostice Bielschowského-Jánského typu familiární amaurotické idiotie. The help of electroencephalography in the diagnosis of Bielschowsky-Jansky type of familial amaurotic idiocy. Ceskoslovenská Pédiatrie, 26, 371-375.

López Martín, V., Pascual Castroviejo, I., and Rodríguez Costa, T. (1974). Importancia de la electroencefalografía con fotoestimulación en la Ceroido-Lipo- 
fuscinosis Neuronal. Anales Españoles de Pediatria, 7, 214-221.

Mastropaolo, C., Pampiglione, G., and Stephens, R. (1971). EEG studies in 22 children with sulphatide lipidosis (metachromatic leucodystrophy). Developmental Medicine and Child Neurology, 13, 20-31.

Mayou, M. S. (1904). Cerebral degeneration with symmetrical changes in the maculae in three members of a family. Transactions of the Ophthalmological Society of the United Kingdom, 24, 142-145.

Pampiglione, G. (1956). Some anatomical considerations upon electrode placement in routine EEG. Proceedings of the Electrophysiological Technologists Association, 7, 20-30.

Pampiglione, G. (1961). EEG in some inborn errors of metabolism. Proceedings of the VII International Congress of Neurology, Rome. Società Grafica Romana, 1, 53-63.

Pampiglione G. and Harden, A. (1973). Neurophysiological identification of a late infantile form of 'neuronal lipidosis'. Journal of Neurology, Neurosurgery, and Psychiatry, 36, 68-74.

Pampiglione, G. and Harden, A. (1974). An infantile form of neuronal 'storage' disease with characteristic evolution of neurophysiological features. Brain, 97, 355-360.

Pampiglione, G. and Lehovský, M. (1968). The evolution of EEG features in Tay-Sachs' disease and amaurotic family idiocy in 24 children. In Clinical Electroencephalography in Children. pp. 287-306. Edited by P. Kellaway and I. Petersén. Grune and Stratton: New York and London.

Pampiglione, G., Privett, G., and Harden, A. (1974).
Tay-Sachs disease: neurophysiological studies in 20 children. Developmental Medicine and Child Neurology, 16, 201-208.

Sachs, B. (1887). On arrested cerebral development with special reference to its cortical pathology. Journal of Nervous and Mental Disease, 14, 541-553.

Santavuori, P. (1973). EEG in the infantile type of socalled neuronal ceroid-lipofuscinosis. Neuropädiatrie, 4, 375-387.

Santavuori, P., Haltia, M., and Rapola, J. (1974). Infantile type of so-called neuronal ceroid-lipofuscinosis. Developmental Medicine and Child Neurology, 16, 644-653.

Santavuori, P., Haltia, M., Rapola, J., and Raitta, C. (1973). Infantile type so-called neuronal ceroidlipofuscinosis. Part 1. A clinical study of 15 patients. Journal of the Neurological Sciences, 18, 257-267.

Sjögren, T. (1931). Die juvenile amaurotische Idiotie. Klinische und erblichkeitsmedizinische Untersuchungen. Hereditas (Lund), 14, 197-426.

Spielmeyer, W. (1905). Weitere Mittheilung über eine besondere Form von familiärer amaurotischer Idiotie. Neurologisches Centralblatt, 24, 1131-1132.

Tay, W. (1881). Symmetric changes in the region of the yellow spot in each eye of an infant. Transactions of the Ophthalmological Society of the United Kingdom, 1 55-57.

Vogt, H. (1905). UUber familiäre amaurotische Idiotie un verwandte Krankheitsbilder. Monatsschrift für Psych atrie und Neurologie (Basel), 18, 161-171 and 310-357응

Zeman, W. and Dyken, P. (1969). Neuronal ceroid lipofuscinosis (Batten's disease). Relationship t amaurotic family idiocy. Pediatrics, 44, 570-583. 